\title{
A comparison between qualitative and quantitative histories: the example of the Efficient market hypothesis.
}

\author{
Franck Jovanovic \\ TELUQ University, CIRST, and LÉO - Université d'Orléans
}

\begin{abstract}
This paper uses the example of the history of the efficient market hypothesis (EMH) and the citation analysis in order to investigate some differences between qualitative history and a quantitative history. The history of the EMH provides a telling example of the way quantitative analyses can supply different perspectives on the qualitative history of this hypothesis or complement it. For instance, since the EMH was proposed, several criticisms emerged (two of the most well-known are the tautological character of its mathematical demonstration and its capability to be tested with certainty). In addition, the definition and the scope of this hypothesis have been modified several times. Although the qualitative history of the EMH refers to these criticisms and these alternative definitions and scopes, the qualitative tools cannot provide a clear measure of the impact of these criticisms and these modifications among economists. By studying the dissemination of the EMH, its major criticisms, and the answers economists provided, a citation analysis sheds different light on the history of the EMH.
\end{abstract}

Keywords: efficient market hypothesis, history of finance, qualitative history, quantitative history 


\section{Introduction}

This paper aims at comparing qualitative and quantitative histories of the efficient market hypothesis $(\mathrm{EMH})$, which is one of the cornerstones of financial economics (Fama 1991, Jovanovic 2010, Jovanovic and Schinckus 2017, Malkiel 1992, Mehrling 2005, Poitras 2006, 2009, Poitras and Jovanovic 2007, 2010, Rubinstein 1975, Zuckerman 2011). Recently, in their edited book on the historiography of recent economics, Weintraub and Düppe (2018) gave the opportunity to investigate how quantitative approaches in history of economics complements qualitative approaches. In the same vein, my goal is not to provide exhaustive quantitative and qualitative analyses of the history of the EMH; it would rather investigate how both methods are complementary for drawing this history. First of all, and as section 4 will detail, it is worth mentioning that several quantitative and qualitative methods exist for studying the history of economics (Cherrier 2017, Claveau and Gingras 2016, Claveau and Herfeld 2018, Dorian 2018, Edwards 2017, Giraud 2018, Svorenčík 2018, Weintraub and Düppe 2018). The history of the EMH provides a telling example of the way quantitative analyses can supply different perspectives on the qualitative history or complement it. Indeed, to date, the history of the EMH has been mainly studied with qualitative approaches. However, the rare quantitative analyses that have been made provided new results and perspectives on the history of this hypothesis (Daemen 2010, Fourcade and Khurana 2017, Jovanovic 2012, Pardo-Guerra 2016, Polillo 2015). For instance, and as this article will detail, since the EMH was proposed, several criticisms emerged. Although the qualitative history of the EMH refers to these criticisms and the alternative definitions and scopes of the EMH, traditional tools didn't provide a clear measure of the impact of these criticisms among economists. Consequently, the qualitative history can have several biases. By studying the dissemination of the $\mathrm{EMH}$, its major criticisms, and the answers economists provided, quantitative methods may shed new light on the history of the EMH.

This is the aim of this article: what can we learn from a comparison between qualitative and quantitative histories of the EMH. For doing this, the following section will sum up the qualitative history of the EMH. Afterwards three key moments of this qualitative history will be selected: the dissemination of Louis Bachelier's work, the influence of Paul Cootner's seminal 1962 article, and the debate between Eugene Fama and Stephen LeRoy about the definition of the EMH. A third section will use a citation analysis, which is a very popular quantitative method $^{1}$, for studying these moments. For each of these moments, the quantitative history that will be drawn from this citation analysis will be compared to the qualitative history. Finally, a fourth and last section will discuss some relations between quantitative and qualitative histories considering the citation analysis used.

\section{The qualitative history of the EMH: a brief summary}

The EMH was created during the 1960s to give a theoretical explanation of the random character of stock market prices. Its formulation claims that stock prices reflect all available information, and that, consequently, the actual price of a security is equal to its intrinsic value. In addition, because new information arrives randomly, stock prices fluctuate randomly. The starting point of the history of the EMH was provided by some of the first theoreticians, who, in order to support and legitimize their theoretical conceptions, embedded their models, theories and hypotheses in a coherent chronological sequential order from past works to their own works (Jovanovic 2008). Fama (1965,

\footnotetext{
${ }^{1}$ For a historical surveys of the history of bibliometrics, see Edwards (2017).
} 
1970,1991 , etc.) is one of these contributors who provided a chronological presentation of the construction of the EMH; Cootner (1964) is the other major actor. However, these canonical histories, written by the actors themselves during the years that led to the creation of the EMH, voluntary ignored facts that could contradict or diminish the models, theories and hypotheses used by these actors. A few decades later, authors who were not direct actors started discussing, criticizing and improving these canonical histories with new historical facts and perspectives, creating the structural history of the EMH we know nowadays ${ }^{2}$. Let me briefly remind this qualitative history of the EMH we know ${ }^{3}$ and from which we will select the three moment that will study in the next section.

\subsection{Origins}

The idea that stock prices fluctuate randomly was not new: in 1863, a French broker's assistant [employé d'agent de change], Jules Regnault (1863), had already suggested it. Regnault was the first author to put forward this hypothesis, to validate it empirically, and to give it a theoretical interpretation. Then, in 1900, Louis Bachelier, a French mathematician, used Regnault's hypothesis for developing the first mathematical model of Brownian motion, which has been largely used for testing the EMH. He was also the first author to apply the trajectories of Brownian motion for pricing conditional forward contract close to option. Unfortunately, at that time, financial economics did not exist as a scientific field, and there was no scientific community interested in developing such research until the 1960s.

Although the early authors did suggest modelling stock prices as a stochastic process, they did not formulate the EMH as it is known today. The EMH was genuinely born in linking three features that originally existed independently of each other: 1) the mathematical model of a stochastic process (random walk, Brownian motion, or martingale); 2) the concept of economic equilibrium; 3) statistical results about the unpredictability of stock market prices. The EMH's creation only took place between 1959 and 1976, when a large number of economists became familiar with these three features. Between Regnault's and Bachelier's time and the development of the EMH, there were no theoretical preoccupations per se about the random character of stock prices. Although some works existed, they were only empirical and aimed at comparing stock price fluctuations with random simulations in order to find similarities. Cowles (1933, 1944), Cowles and Jones (1937), Working $(1934,1935)$ and Kendall $(1953)$ are the key authors of this period.

The situation changed at the end of the 1950s and during the 1960s due to two particular events. First, modern probability theory (and consequently the theory of stochastic processes) became usable for non-mathematicians. Significantly, economists were attracted to the new formalisms by some features that were already familiar consequences of economic equilibrium. Most important, the zero expected profit when prices follow a Brownian motion reminded economists of the zero marginal profit in the equilibrium of a perfectly competitive market. Second, research on the stock market became more and more popular amongst scholars in U.S. business schools. This context raised awareness about the need for theoretical investigations, and these investigations in turn allowed for the creation of the EMH.

\footnotetext{
${ }^{2}$ As Stone (1979) reminded, we can oppose the narrative history, which is descriptive, to the structural history, which is analytical.

${ }^{3}$ The main lines of qualitative history of the EMH are nowadays well known (Delcey 2017, Frydman and Goldberg 2010, Jovanovic 2008, 2010, Sewell 2011, Thicke 2017).
} 
Financial economists did not speak immediately of the EMH; they talked about "random walk theory". Following his empirical results, Working (1956) was the first author to suggest a theoretical explanation to the random character of stock market prices; he established an explicit link between the unpredictable arrival of information and the random character of stock market price changes. However, this paper made no link with economic equilibrium and, probably for this reason, it was not largely diffused. Instead it was Roberts $(1959,7)$, a professor at the University of Chicago, who first suggested a link between economic concepts and the random walk model by using the "arbitrage proof" argument that had been popularized by Modigliani and Miller (1958). Then, Cowles $(1960,914-5)$ made an important step by identifying a link between financial econometric results and economic equilibrium. Finally, two years later, Cootner $(1962,25)$ linked the random walk model, information, and economic equilibrium, and exposed the idea of the EMH, although he did not use that expression, by describing how this "perfect market" should work.

\subsection{Establishment}

Cootner (1962) had the essential idea of the EMH, but he did not make the crucial link because he considered that stock price variations were not purely random and that stock markets are not perfect. Economists from MIT (as Samuelson) and Stanford University (as Working) defended this point of view. By contrast, economists from the University of Chicago claimed that real stock markets were perfect, and so they were more inclined to characterize them as efficient. Thus, it was a scholar from the University of Chicago, Eugene Fama, who formulated the EMH. In his 1965 Ph.D. thesis, Fama gave the first theoretical account of the EMH assuming the existence of "sophisticated traders" who, due to their skills, make a better estimate of intrinsic valuation than other agents do by using all available information. Provided that such traders have access to sufficient financial resources, their activity of buying under-priced assets and selling overpriced assets will tend to make prices equal intrinsic values, and also to eliminate any expectation of profit from trading. Linking these consequences with the random walk model, Fama added that because information arrives randomly, stock prices have to fluctuate randomly. Fama thus offered the first clear link between empirical results about stock price variations, the random walk model, and economic equilibrium. The EMH was born - and with it financial economics.

Five years after, Fama (1970) provided a mathematical demonstration of the EMH. He simplified his first definition by making the implicit assumption of a representative agent. He also used a less restrictive stochastic process, the martingale model. For Fama's purposes, the most important attraction of the martingale formalism was its explicit reference to a set of information, $\Phi_{\mathrm{t}}$, $E\left(P_{t+1} \mid \Phi_{t}\right)-P_{t}=0$. As such, the martingale model could be used to test the implication of the $\mathrm{EMH}$ that, if all available information is used, the expected profit is null. This idea led to the definition of an efficient market that is generally used nowadays: "a market in which prices always "fully reflect" available information is called "efficient"” (1970, 383).

\subsection{Debates}

In 1976, LeRoy criticised Fama's demonstration showing that it was tautological and not testable. Fama (1976a) answered LeRoy by changing his definition, and admitted that any test of the EMH was a test of both market efficiency and the model of equilibrium used by investors. This proved to be a fateful admission. In retrospect, it is clear that the theoretical content of the EMH consisted in its suggestion of a link between some mathematical model, some empirical results, and some 
concept of economic equilibrium. The link with economics allowed to associate these works in finance with a discipline already recognize as scientific. The precise linkage proposed by Fama was however only one of many possible linkages, as subsequent literature would demonstrate. LeRoy (1973) and Lucas (1978) provided theoretical proofs that the EMH and the martingale hypothesis are two distinct ideas: martingale is neither necessary nor sufficient for an efficient market. In a similar way, Samuelson (1973), who gave a mathematical proof that prices may be permanently equal to the intrinsic value and fluctuate randomly, explained that it cannot be excluded that some agents make profits, contrary to the original definition of the EMH.

Some other authors criticized the very relevance of efficient markets. For instance, Grossman and Stiglitz (1980) argued that because information is costly, prices cannot perfectly reflect all available information. Consequently, they considered that perfectly informationally efficient markets are impossible. In 1991, Fama answered by explaining that the statement according to which security prices fully reflect all available information must be considered as a "strong version of the hypothesis [for which] information and trading costs, the costs of getting prices to reflect information, are always 0 ... Since there are surely positive information and trading costs, the extreme version of the market efficiency hypothesis is surely false" (1991, 1575). He added that "each reader is then free to judge the scenarios where market efficiency is a good approximation (that is, deviations from the extreme version of the efficiency hypothesis are within information and trading costs) and those where some other model is a better simplifying view of the world" (1991, 1575).

These problems were not the only ones the EMH faced. The definition of the EMH is polymorphous and has changed depending on the emphasis placed by each author on one particular feature. For instance, Fama et al. (1969) defined an efficient market as "a market that adjusts rapidly to new information"; Jensen (1978) considered that "a market is efficient with respect to information set $\theta_{t}$ if it is impossible to make economic profit by trading on the basis of information set $\theta_{t}$ "; Beaver (1981) stated that "market efficiency with respect to an information item means that prices act as if everyone knows that information"; according to Malkiel (1992) "the market is said to be efficient with respect to some information set $[\ldots]$ if security prices would be unaffected by revealing that information to all participants. Moreover, efficiency with respect to an information set [...] implies that it is impossible to make economic profits by trading on the basis of [that information set]". Extensively, the definition based on the impossibility to make profit can be associated with Harrison and Kreps (1979) and Harrison and Pliska's (1981) theoretical framework that defined efficiency by the arbitrage-free. Fama qualified this definition as "a weaker and economically more sensible version" of the EMH $(1991,1575)$.

The situation is similar as regards to tests: the type of test used depends on the definition used by the authors, and authors disagree on which tests allow to validate or to reject the EMH. However, the EMH has been extensively tested and many tests pointed out several profit opportunities, which constitute anomalies regarding the EMH predictions. In the 1980s there emerged two alternative theoretical approaches that took as their starting point a questioning of these empirical anomalies and the polymorphous definition of the EMH: behavioral finance and financial market microstructure. Both directly called upon the EMH. Financial market microstructure focuses on how specific trading mechanisms and how strategic behaviors affect the price formation process. A central idea is that asset prices do not fully reflect all available information even if all participants are rational. Indeed, information may be unequally distributed between, and differently interpreted 
by market participants. This hypothesis stands in total contradiction to the EMH. The second alternative approach is behavioral finance that studies the influence of psychology on the behavior of financial practitioners and the subsequent effect on markets. In this perspective, markets are presumed to be informationally inefficient. Fama answered in 1998 by claiming that these studies "rarely test a specific alternative to market efficiency. Instead, the alternative hypothesis is vague market inefficiency. This is unacceptable. Like all models, market efficiency (the hypothesis that prices fully reflect available information) is a faulty description of price formation. Following the standard specific rule, however, market efficiency can only be replaced by a better specific model of price formation, itself potentially rejectable by empirical tests" (Fama 1998, 284).

Finally, despite these problems and the ambiguous status of the EMH, the hypothesis has laid down one of the cornerstones of financial economics and, in a certain way, created the field. In 2013, the "Nobel Prize in economics" was awarded to Eugene Fama, mainly for his work related to financial economics and the EMH.

\section{A quantitative history of the EMH: three key moments}

This third part will focus on three key moments of the history of the EMH in order to analyse the kind of history that emerges from a quantitative analysis of citation analysis. It also studies how such quantitative history interacts with the qualitative history of the EMH. As mentioned, these three moments have been selected from the qualitative history by opposition of the approach used for instance by Claveau and Gingras (2016), which doesn't pre-selected elements from qualitative history.

\subsection{The dissemination of Louis Bachelier's work}

The first key moment concerns Louis Bachelier who introduced continuous-time probabilities by using stock market prices. Bachelier was the first to formulate the Brownian motion, which has been largely used for testing the EMH (even if such tests are not relevant). This author was generally considered as a formidable forerunner who was forgotten until the mid-1950s ${ }^{4}$. However, by using a citation analysis of the two major publications of Bachelier, his doctoral thesis, Théorie de la spéculation (1900), and his major book Calcul des probabilities (1912), Jovanovic (2012) provided a different perspective of the dissemination of Louis Bachelier's work. First of all, let me present briefly these two publications.

The Théorie de la spéculation was his first publication. It was the first step of his research program, which was the construction of a general and unified theory of the calculation of probabilities exclusively on the basis of continuous time ${ }^{5}$. This first step was the introduction of continuous time probabilities by demonstrating the equivalence between the results obtained in discrete time and in continuous time. Then Bachelier used the stock market prices for proving the usefulness of this equivalence. His thesis played a key role in his research program: the "Theory of speculation has mainly been useful from the point of view of pure science; it necessarily introduced into the calculation of probabilities the notion of time and absolute continuity; it has given rise to the theory

\footnotetext{
${ }^{4}$ Bernstein (1992), Merton (1998), Scholes (1998), Dimson and Mussavian (1999, 2000), Whelan, Bowie, and Hibbert (2002), or Davis and Etheridge (2006).

${ }^{5}$ See Courtault et al. (2002), Ben-El-Mechaiekh and Dimand (2018) and Jovanovic (2000).
} 
of continuous probabilities [...]. If speculation did not exist, we would have to invent it" (Bachelier 1914, 177-8).

Bachelier considered the Calcul des probabilités as his most important publication, which "is the first book that surpasses the great treatise of Laplace" (Bachelier 1921). This book was dedicated to mathematicians and other specialists of the calculation of probabilities. Its object was to "make known new methods and new results that represent, from certain points of view, a complete transformation of [the calculation of probabilities]. The basis of these new studies is the conception of continuous probabilities [...]" (Bachelier 1912, III) ${ }^{6}$. The book was based on Bachelier's notes for lectures that he gave at the University of Paris between 1909 and 1914 on "Probability calculus with applications to financial operations and analogies with certain questions from physics". (Taqqu 2001, 17). And more important, a large part of this book is dedicated to the Théorie de la spéculation. Five chapters out of 23 were devoted to this theory, including a complete presentation of it $^{7}$. In other terms, any author who read the Calcul des probabilités knew the Théorie de la speculation.

The citation analysis of these two publications provided a new perspective on the influence of Bachelier's finance ideas. Figure 1 shows that this author was first known for his Calcul des probabilités; and that his thesis began to be cited only in 1959, after which point Calcul des probabilités was barely cited at all.

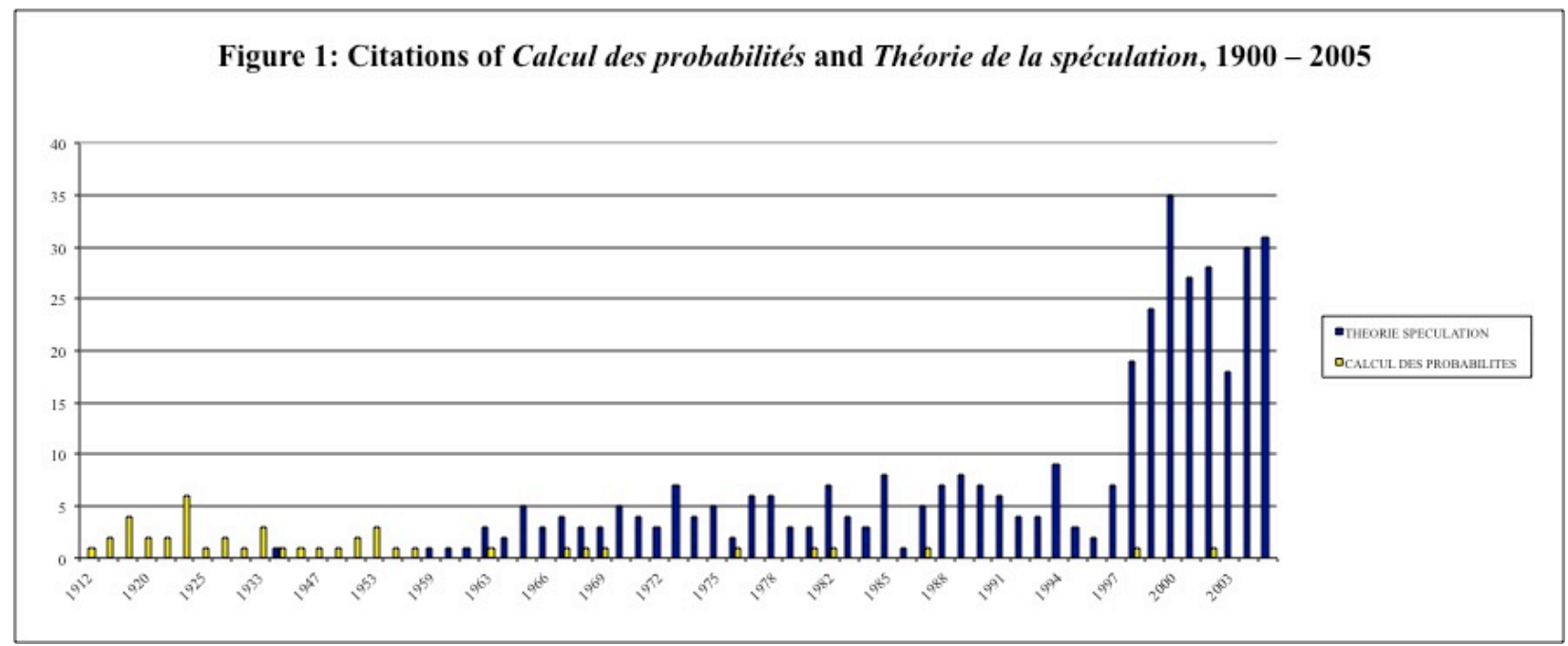

This quantitative analysis reveals two very distinct periods in the dissemination of Bachelier's work: 1) from 1912 to 1959, when only Calcul des probabilités was cited; 2) 1959 onwards, when the thesis has been almost the sole publication cited. If we consider which publications economists cited (Figure 2), we observe that articles published in economics journals cite almost exclusively Bachelier's thesis.

\footnotetext{
${ }^{6}$ In 1914, Bachelier published a book for non-specialists, Le Jeu, la Chance et le Hasard.

${ }^{7}$ It is worth mentioning that Bachelier presented his Theory of speculation in all of his books. In his last book, published in 1938, his presentation "was more concise and readable and more mathematically elegant than his earlier statements of the theory" (Ben-El-Mechaiekh and Dimand 2018, 41).
} 


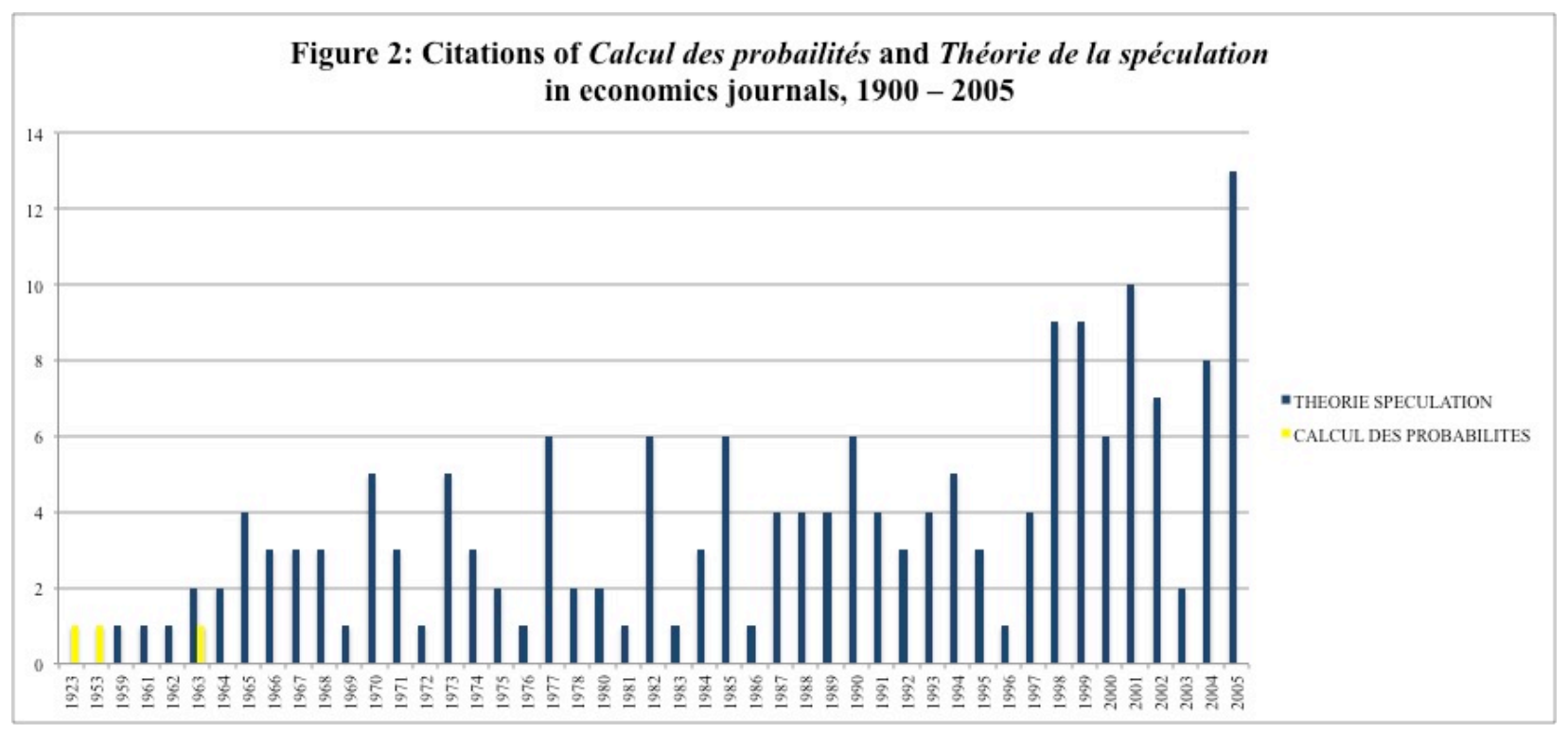

Per se, this quantitative statement is hardly useful. However, given the crucial role of modern probability theory in the construction of the EMH (Davis and Etheridge 2006, Jovanovic 2008), it sheds new lights on the history of the EMH. Let me remind that modern probability theory was properly created in the 1930s, in particular through the work of Kolmogorov, who proposed its main founding concepts (Von Plato 1994). Between the end of the 19th century and the 1930s, the only work being carried out in this new field was the particularly innovative work of mathematicians and physicists. Bachelier was one of these mathematicians. But it was not until after World War II that the Kolmogorov's axioms became the dominant paradigm in this discipline (Shafer and Vovk 2005, 54-5). It was also from the 1950s that nonspecialists, and hence economists, began using the tools of modern probability theory. More precisely, economists were unable to read the new mathematics developed in Bachelier's doctoral thesis until the 1960s (Davis and Etheridge 2006, Jovanovic 2012). Consequently, the application of continuous time probabilities to financial markets could not be performed by economists before the end of the 1950s.

Considering this additional information, the citations analysis of Bachelier's work provides complementary results to the qualitative history of the EMH. First, Bachelier's work was known since 1912 (not just since the 1950s). Second, the discovery of Bachelier's work by economists provided not so much an analytical support, but a kind of handy "off-the-shelf" historical ancestry for the nascent field of modern finance. Indeed, before the 1960s, while some economists knew Bachelier's work and its applications for the study of financial markets, they did not really engage them.

To conclude, qualitative and quantitative histories are complementary in this first example. This is a telling example of a way in which citation analysis can improve the qualitative history of the EMH by showing the diffusion and the impact of authors or publications (like the first result). It provides also the opportunity to reinforce or support a hypothesis related to the history of economics (like the second result).

\subsection{Paul Cootner's random vs. systematic changes in stock prices}


The second moment concerns the reception of Paul Cootner's seminal 1962 paper, which can be considered as the birth certificate of the intuition of the EMH. More precisely, Cootner $(1962,25)$ first exposed the idea of the EMH, although he did not use that expression. In order to put the following analysis in perspective, it is worth reminding that Cootner is one of the main authors of the EMH's infancy ${ }^{8}$.

The citation analysis shows that Cootner (1962) has been relatively few cited (Figure 3) compared to other seminal papers of financial economics published during the 1960s and the 1970s (i.e. the period of the creation of financial economics as a scientific discipline) ${ }^{9}$. Moreover, the major impact of Cootner's article took place in the 1960s.

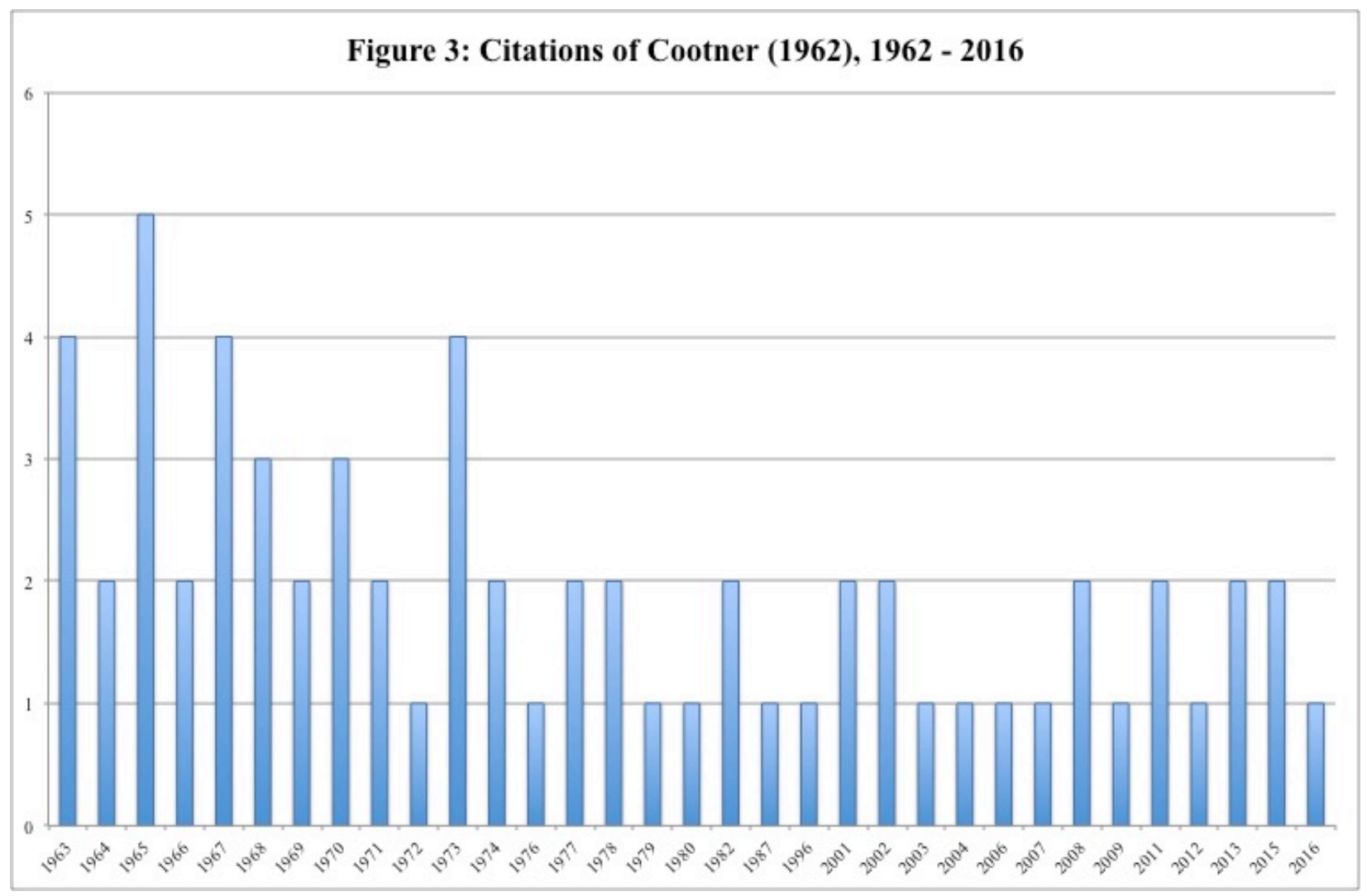

When citations are taken into account, then Cootner (1962) did not have an important impact on the quantitative history of the EMH. However, if we go forward and consider the authors who cited Cootner (1962), an interesting point emerges: the authors of the University of Chicago are those who referred to this article the most (Figure 4).

\footnotetext{
${ }^{8}$ During the 1960s, Cootner supervised more than twenty M.A. and Ph.D. theses in financial economics and became an essential figure in the development of the discipline at MIT, before moving to Stanford University where Working was. In 1964, he edited the first anthology of articles dedicated to The Random Character of Stock Market Prices. This book also provided the first translation of Bachelier's thesis and contributed enormously to the spread of the random walk model.

${ }^{9}$ I took as the benchmark the seminal papers of financial economics published during the 1960s and the 1970s and cited in social science journals. Cootner (1962) was cited 47 times compared to 473 times in average (with a maximum of 1997 times and the minimum 22 times); it is included in the third-lowest decile.
} 


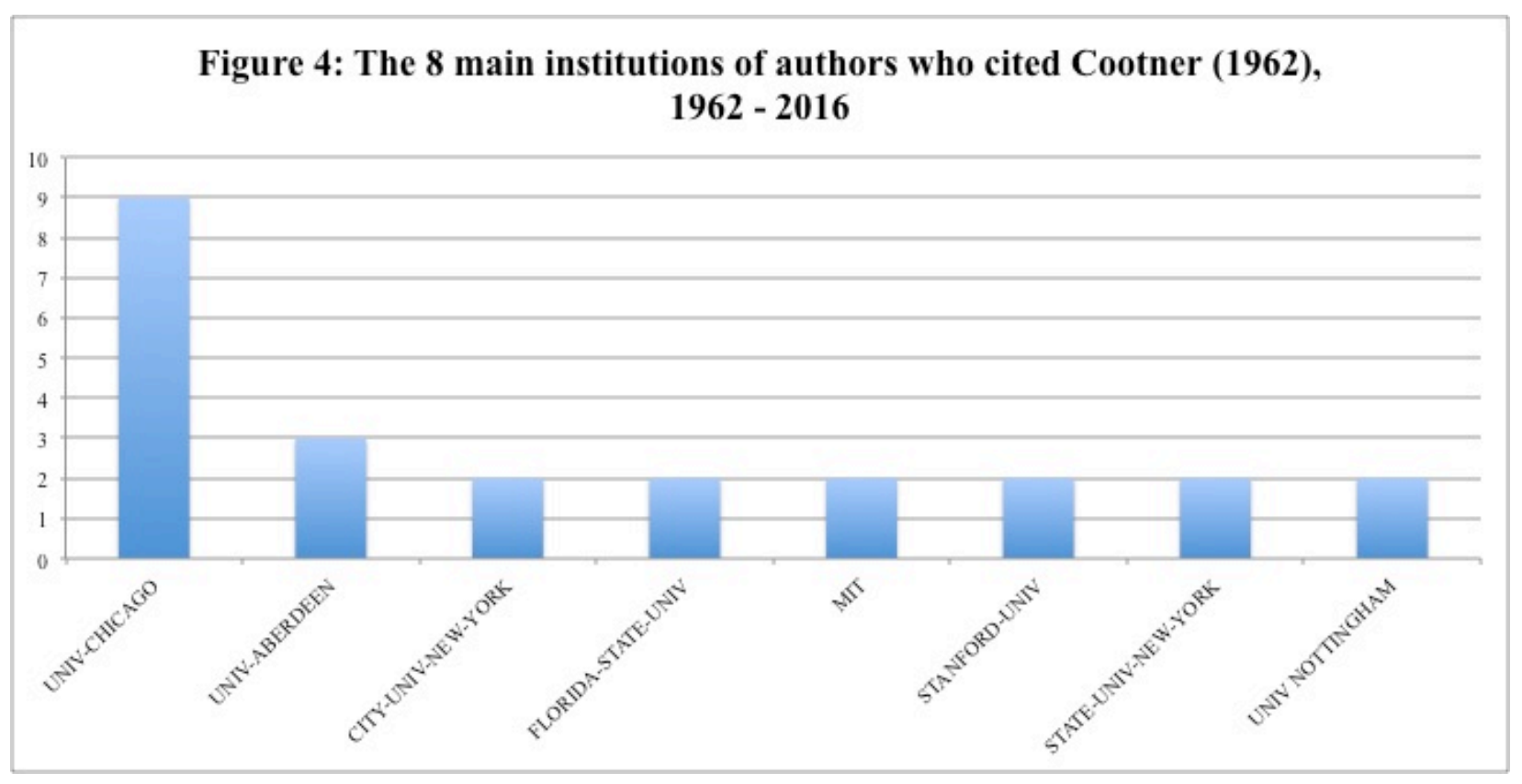

This point may sound paradoxical, since Cootner's article defended the idea that markets are not efficient! A position strongly rejected by authors from the University of Chicago. "To the Chicago School, efficiency was a foundational assumption not to be disputed" (Polillo 2015, 16). It was "the idée fixe of the school" (Niederhoffer 1997, 271). Moreover, during this period, authors from the University of Chicago only cited works that legitimated the EMH (Jovanovic 2008). The fact that authors from the University of Chicago cited Cootner (1962) during the genesis of the EMH underlines the importance of this article. Moreover, this point seems to be reinforced by the fact that since Fama published his 1970 article, authors from the University of Chicago stopped referring to Cootner (1962).

Table 1: Citations of Cootner (1962) by authors from the University of Chicago, 1962 2016

\begin{tabular}{|c|r|}
\hline Year & Frequency \\
\hline 1963 & 1 \\
\hline 1964 & 1 \\
\hline 1965 & 3 \\
\hline 1966 & 2 \\
\hline 1967 & 1 \\
\hline 1970 & 1 \\
\hline Total & $\mathbf{9}$ \\
\hline
\end{tabular}

According to a strict citation analysis, Cootner (1962) should be consider as having a marginal importance in the history of the EMH.

However, additional data reveal a more complex situation. Cootner (1962) provided a theoretical analysis of the random walk character of stock market prices rather than a technical analysis. This point could contribute to explain the low impact of this article. According to Whitley (1986), theoretical articles have had less importance than technical article in finance, given the demand 
from financial institutions to hire new graduates with robust technical skills. Daemen (2010) pointed out the same result: compare to economics, financial economics is much more concerned by predictions rather than explanations, and technical articles are much more frequent than theoretical articles ${ }^{10}$.

Figure 5: kind of articles published in the Journal of Finance, 1946-2008

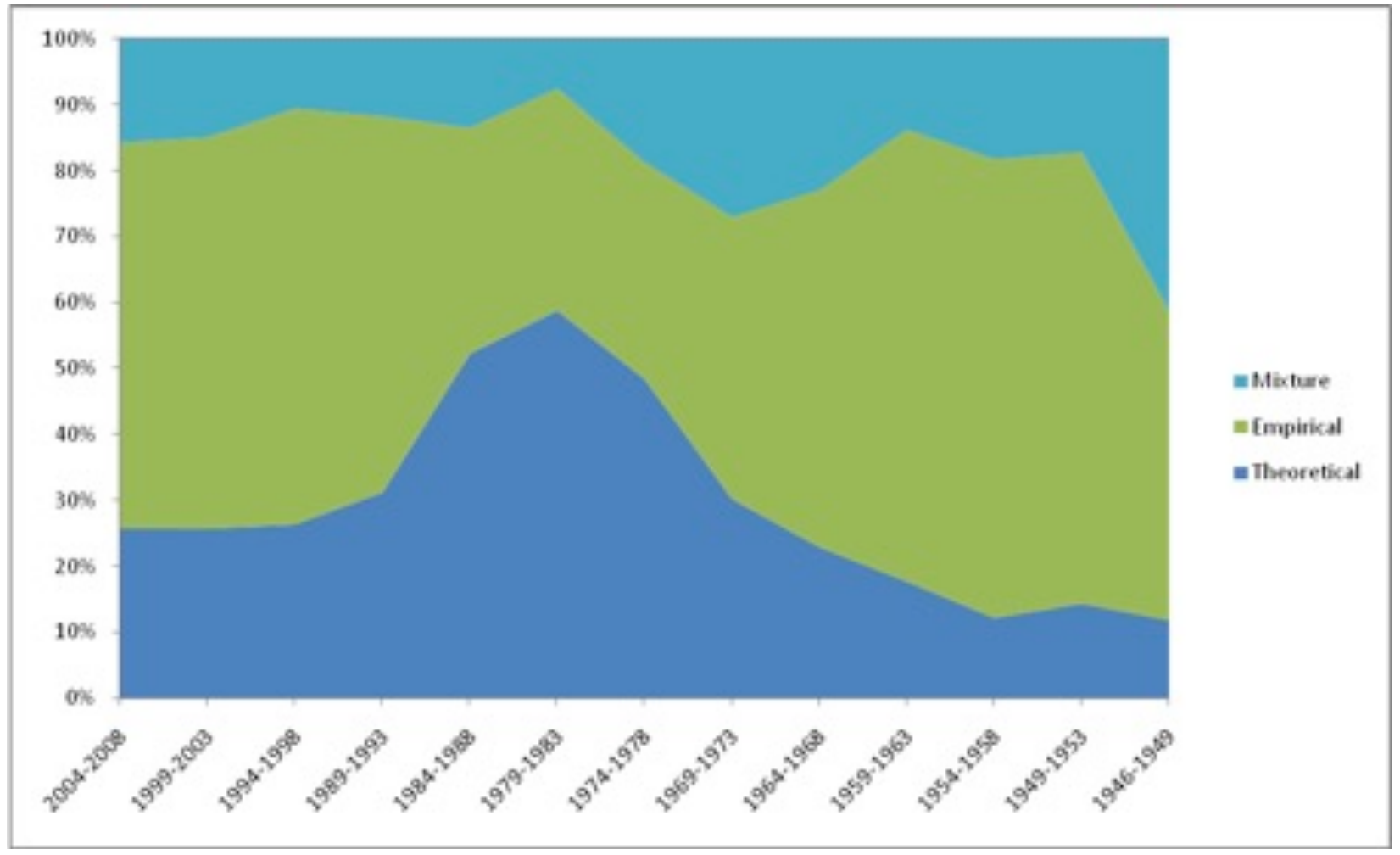

Source: (Daemen 2010, 12).

Given this specificity of financial economics, citation analysis could significantly underestimate the importance of theoretical articles like Cootner's (1962). By opposition to Cootner (1962), Fama systematically made the link between the theoretical and technical aspects of the EMH (i.e. tests), allowing the development of technical studies without theoretical investigations.

To conclude this second example, citation analysis provides a perspective that differs from the qualitative history we know. However, since these two articles are not of the same type (theoretical article versus technical article) this difference should be considered with caution and should be investigated in more detail. Section 4 will come back on this point.

\subsection{Fama and LeRoy's controversy}

Our third moment concerns the debate between Fama and LeRoy about the EMH. In 1976, LeRoy provided the first major theoretical criticism on the EMH, showing that Fama's demonstration is tautological and that the EMH is not testable per se, because any empirical test of the hypothesis is

\footnotetext{
${ }^{10}$ See also Polillo (2015) on the role of empirical methodology in the diffusion of the EMH defended by Fama.
} 
necessarily a joint-test ${ }^{11}$. The test would, then, consist in using a model for setting the equilibrium value of assets - the simplest would be to take the model actually used by the operators - and determining the returns that the available information would generate; then to use the same model with the information that agents use.

In 1976, Fama answered LeRoy by changing his definition of the EMH and by admitting that any test of the EMH is a test of both market efficiency and the model of equilibrium used by investors. Moreover, he modified his mathematical formulation by introducing a distinction between the equilibrium expected return on a security implied by the set of information used by the market and the true expected return implied by the set of information available at the same period. From then on, efficiency presupposed that, using Fama's own terms, the market "correctly" evaluates the "true" density function conditional on all available information. Thus, in an efficient market, the truly perfect model for valuing the equilibrium price is available to agents. To test efficiency, Fama reformulated the notion of "expected return" by introducing a distinction between price - defined by the true valuation model - and the agents' expectations. The test consisted of verifying whether the return expected by the market based on the information used was equal to the expectation of the true return obtained on the basis of all information available. This true return was obtained by using the "true" model for determining the equilibrium price.

Fama proposed testing the efficiency in two ways, both of which relied on the same process. The first test consisted of verifying whether "trading rules with abnormal expected returns do not exist" (1976a, 144). In other words, this was a matter of checking that one could obtain the same return as that provided by the true model of assessment of the equilibrium value on the one hand, and the set of available information on the other hand. The second test would look more closely at the set of information, to verify that "there is no way to use the information $\Phi_{t-1}$ available at $t-1$ as the basis of a correct assessment of the expected return on security $j$ which is other than its equilibrium expected value" (1976a, 145).

At the close of his 1976 article, Fama answered LeRoy's criticism: the new definition of efficiency was a priori testable. Despite Fama's claim, it is not the case. Indeed, it should be noted that the definition of efficiency had changed: Fama now referred to the true model for assessing the equilibrium value. For this reason, testing efficiency required also testing that agents were using the true assessment model for the equilibrium value of assets. Moreover, it is striking to note that the test suggested by Fama is independent of the random nature of stock-market variations. This is because, in this 1976 article, there is no more talk of random walk or martingale; no connection with a random process is necessary to test efficiency. It is worth mentioning that Fama's (1976a) explanation was also reproduced in Fama's largely diffused book, Foundations of finance (1976b). Fama's result about the absence of connexion between stochastic process and the EMH test, should have been surprising given that numerous publications used stochastic processes for testing the EMH. Especially since LeRoy (1973) and Samuelson (1973) provided theoretical proofs that the

\footnotetext{
${ }^{11}$ A joint-test refers to the fact that, on a given market, any test of the efficiency (i.e. the fact prices fully reflect available information) tests at the same time the notion of efficiency and the asset-pricing model used to price securities on this market. In other words, any empirical refutation (or validation) can be due either to the fact that the market is not efficient (or efficient) or that the model used is not appropriate (or appropriate) for the test. In other words, such a joint-test implies that market efficiency per se is not testable per se (Campbell, Lo, and MacKinlay 1997, Cuthbertson 2004, Fama 1976a, 1991, Findlay and Williams 2001, Jovanovic 2010, LeRoy 1976, 1989, Lo 2000).
} 
EMH and the martingale hypothesis are two distinct ideas. Consequently, in 1989, LeRoy published another article that still pointed out problems of the EMH. Two years later, in 1991, Fama provided an update about the EMH in which he came back on the difficulties involved in this joint test (Fama 1991, 1575-6), and also suggested to reformulate the definition and the way to test the EMH. However, this new definition didn't have a real echo among authors.

From the qualitative history perspective, we have a debate between two authors leading to an evolution in the definition of the EMH. However, the citation analysis provides a very different perspective, showing how LeRoy's critique was largely ignored (Figure 6 and 7) $)^{12}$.

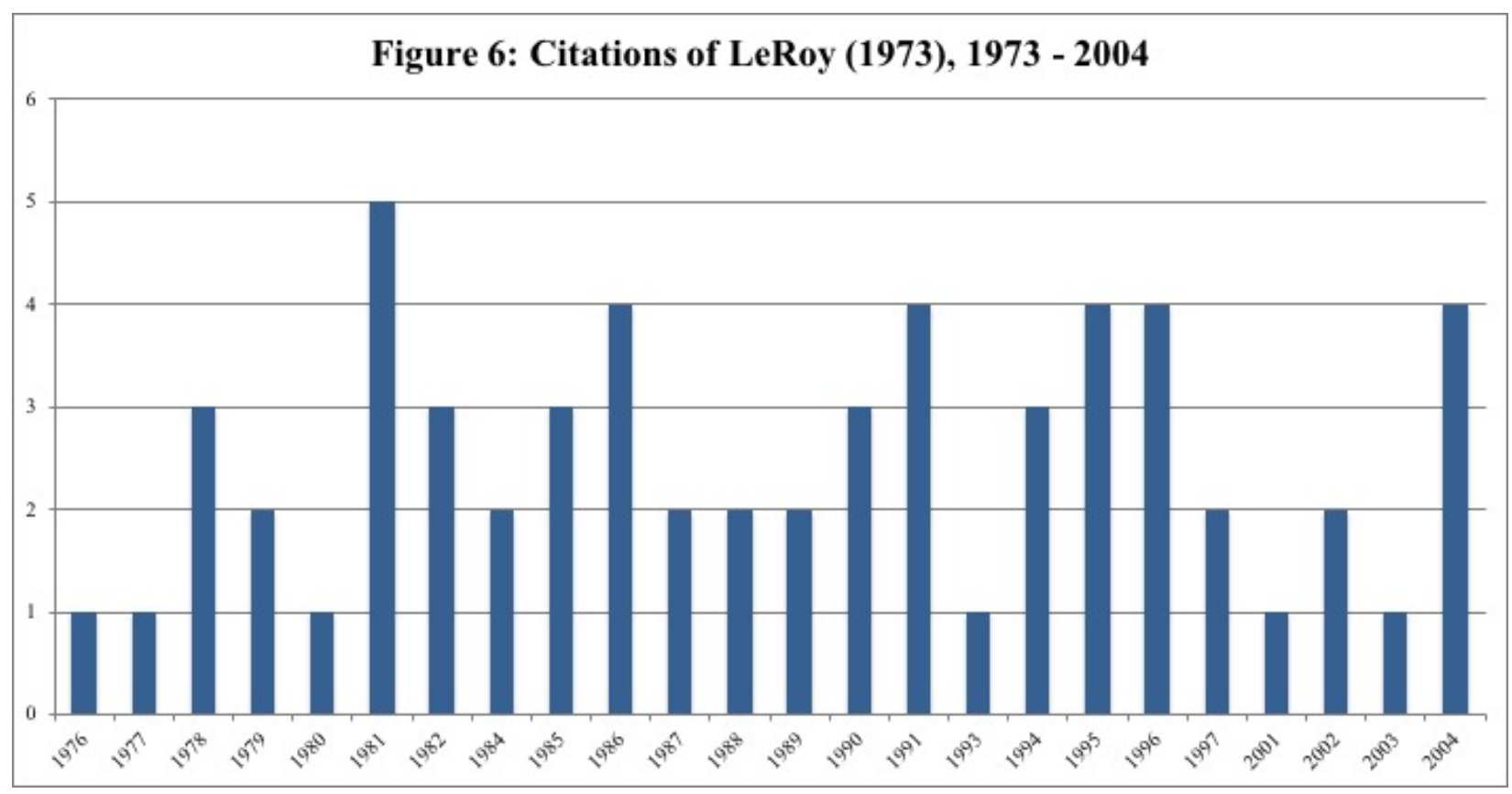

\footnotetext{
${ }^{12}$ It is worth noting that LeRoy (1976) is not necessary a paper that will be cited because it is a criticism or a respond. In other terms, this paper could have an impact while it was not cited, the last section will come back on this point.
} 


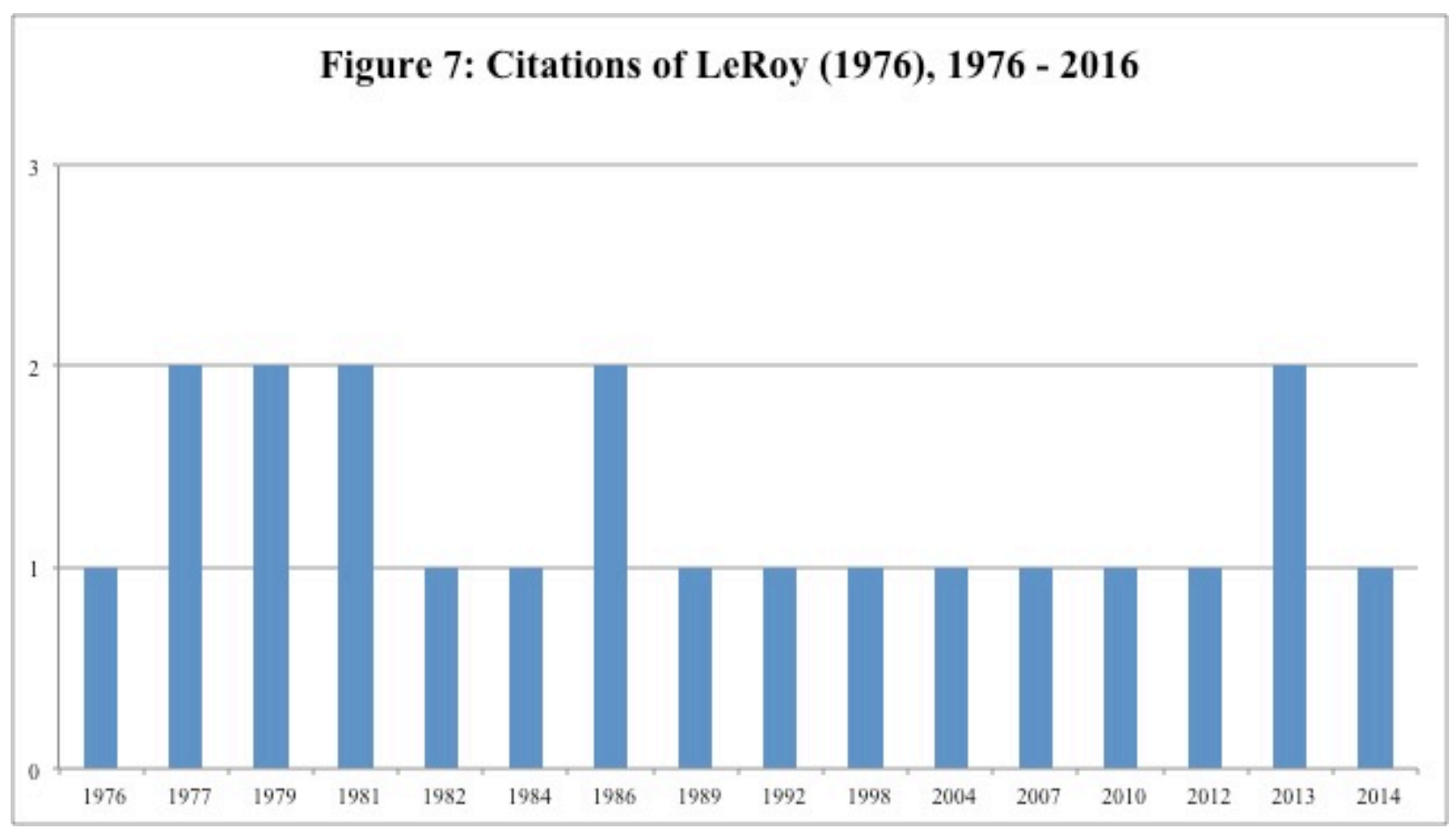

If we remove LeRoy citing his own article, only 16 articles cited LeRoy (1976), including Fama's answer published in the same volume. Before 1989 (the year LeRoy published his second critical article, only 9 articles cited LeRoy (1976). In addition, as Figures 8 and 9 show, excepted Fama's answer, authors from University of Chicago, the University of Pennsylvania and the University of Rochester ${ }^{13}$, completely ignored LeRoy (LeRoy 1973, 1976).

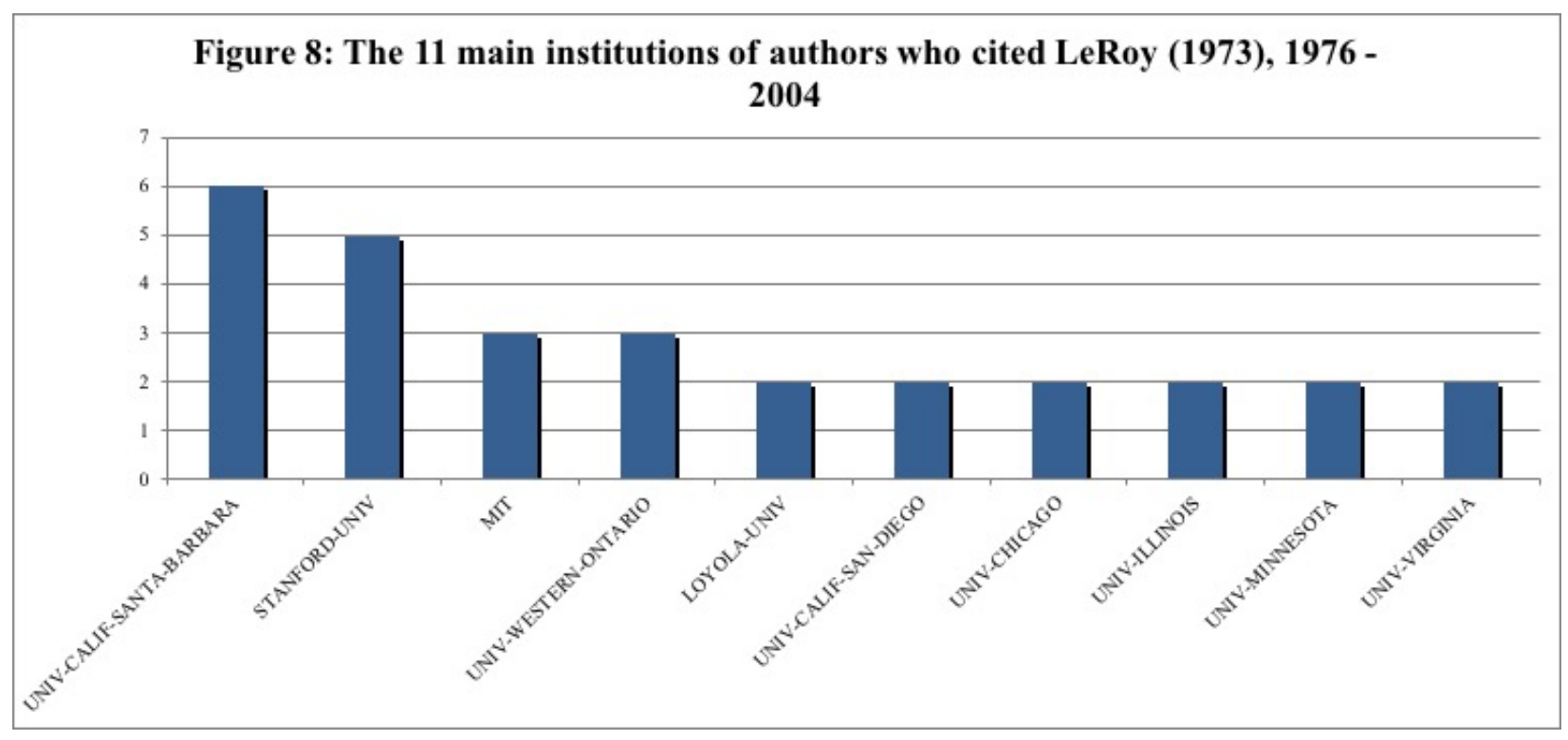

${ }^{13}$ The University of Rochester was a satellite of the University of Chicago (Fourcade and Khurana 2017, 363). 


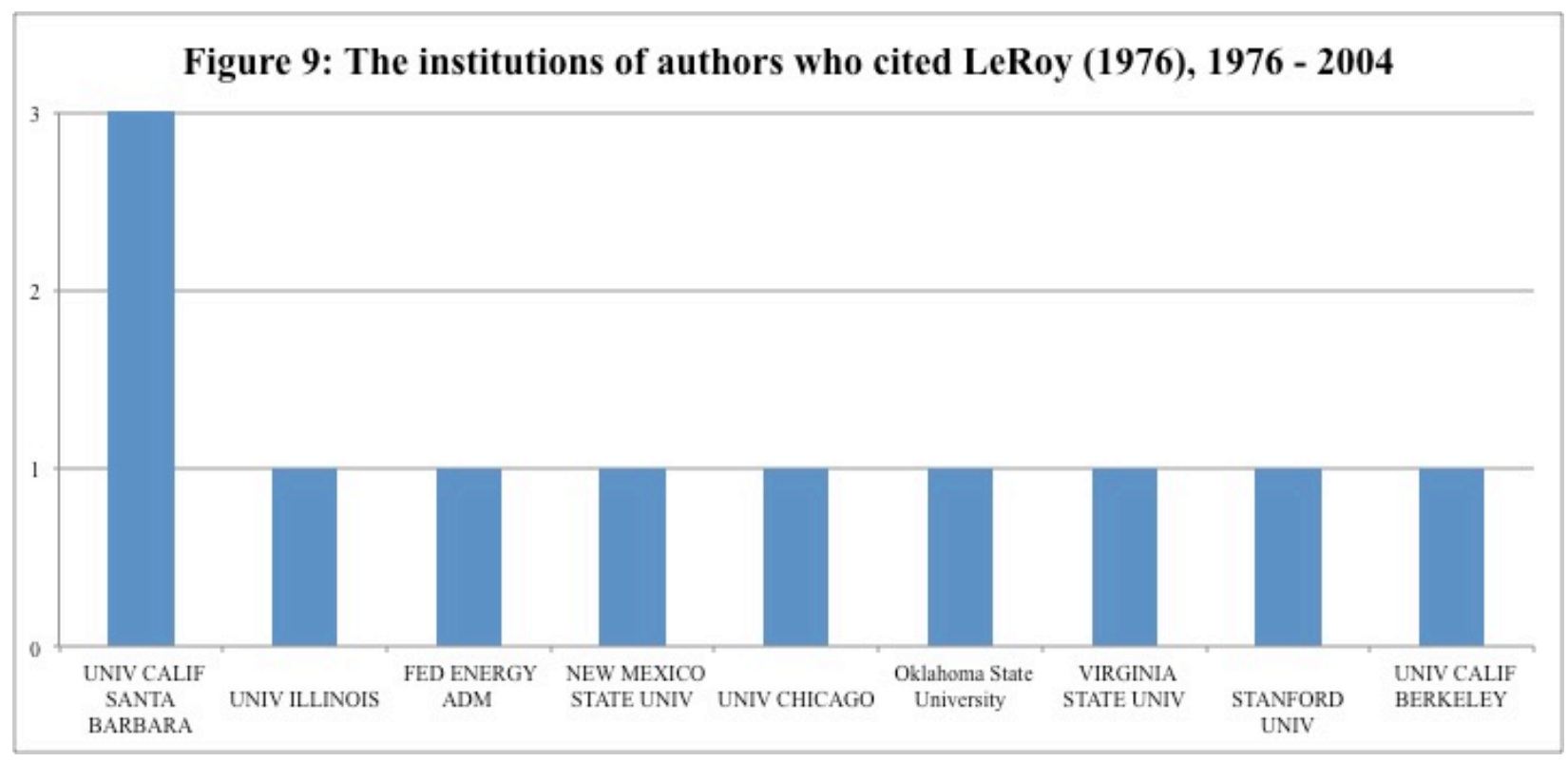

The article published in 1989, in which LeRoy formulated again his criticisms, was more cited (Figure 10).

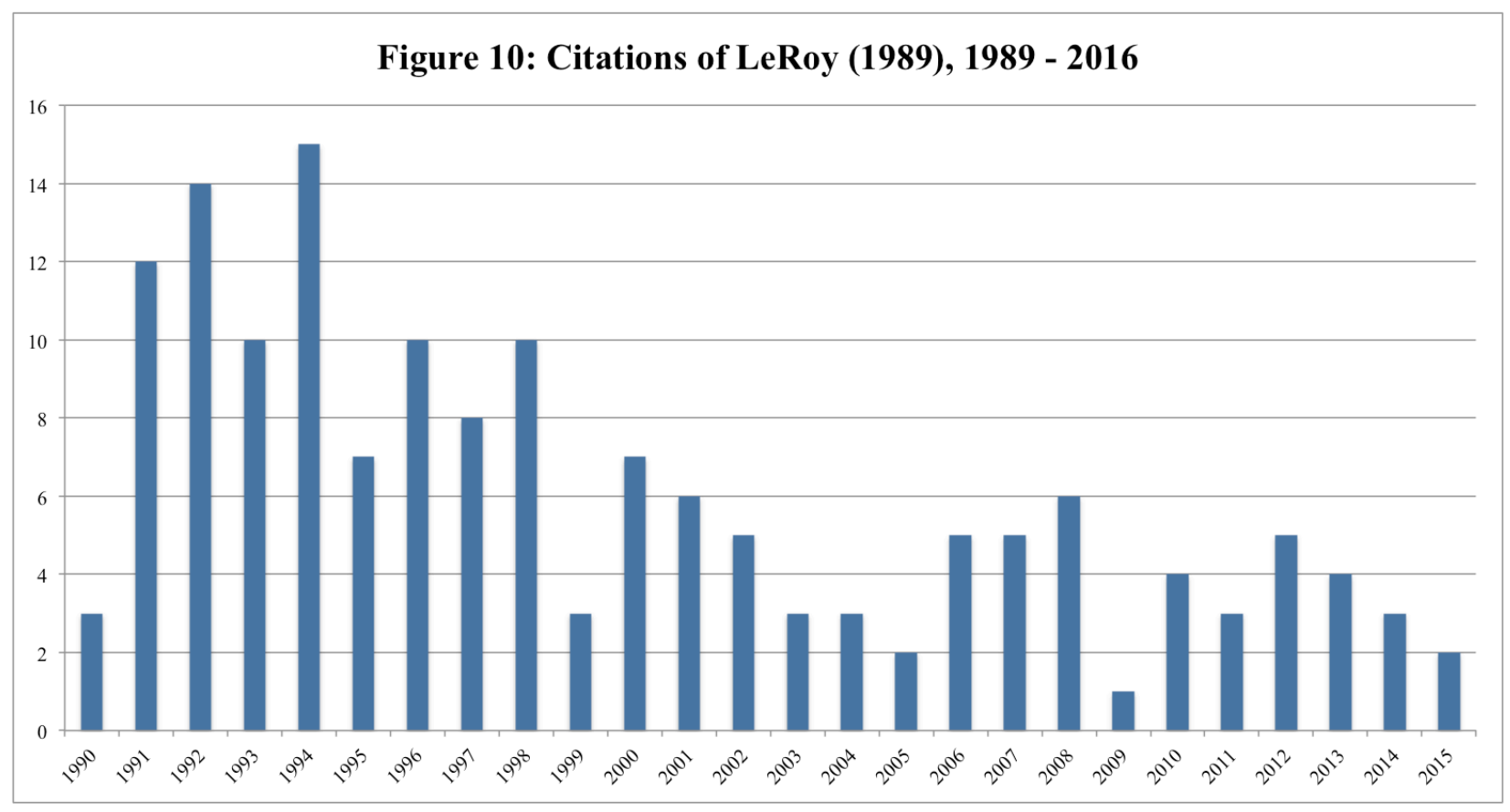

However, it is worth mentioning that the frequency is low compared to our benchmark and to Fama's publications -Fama (1970) was cited 1453 times in the same data sample and Fama (1991) 428 times. It is worth noting that Fama (1970) and Fama et al (1969) are among the most cited articles in economics (Ederington 1979, 781). In addition, and although the authors come from numerous institutions, here again authors from the University of Chicago (2 citations), the University of Pennsylvania ( 1 citation) and the University of Rochester (1 citation) almost ignored LeRoy (1989), and are not part of the main institutions (3 citations and more). 


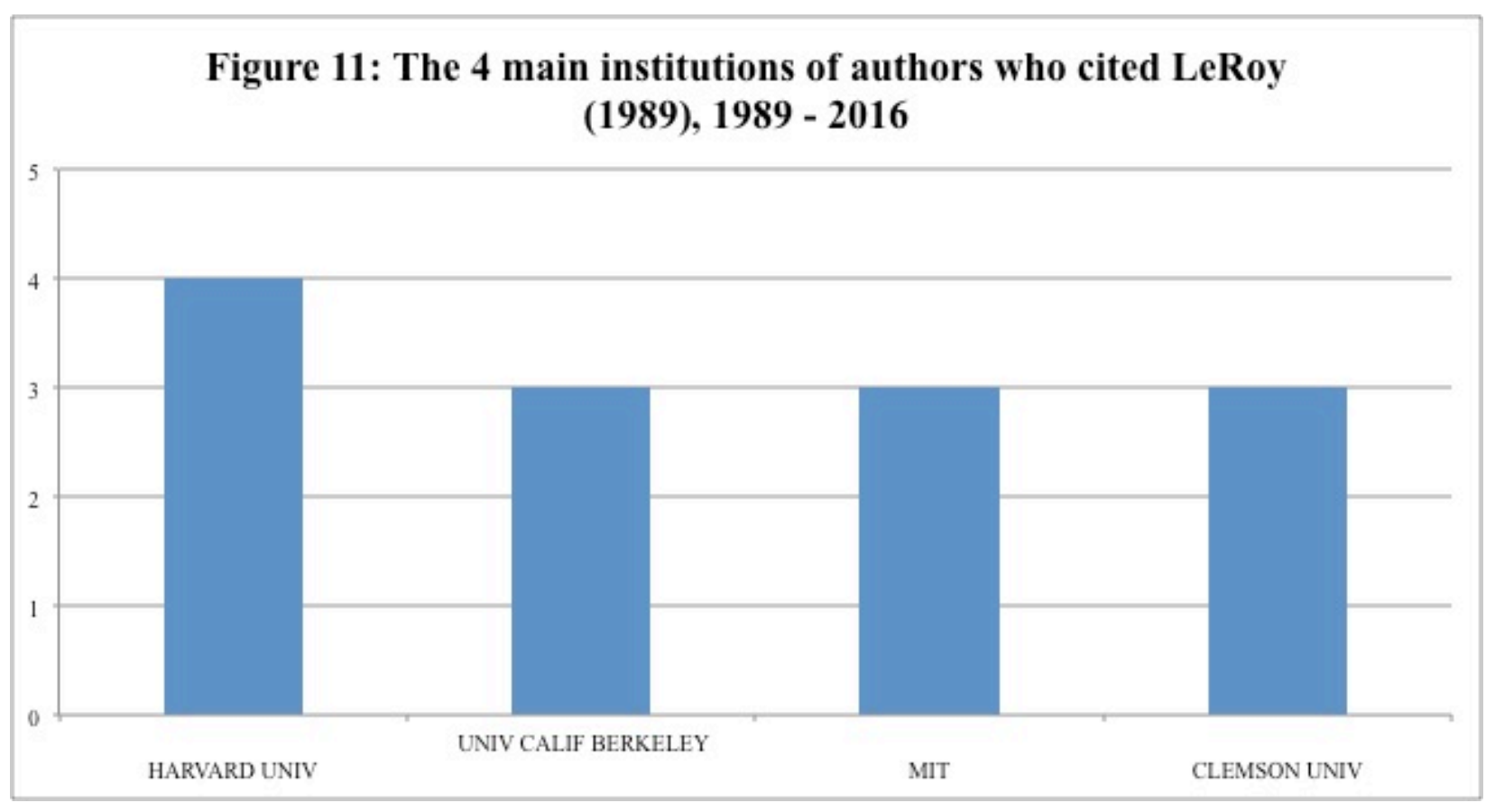

Fama (1976a) was largely ignored too: only 8 articles cited it before LeRoy repeated his criticism in $1989^{14}$.

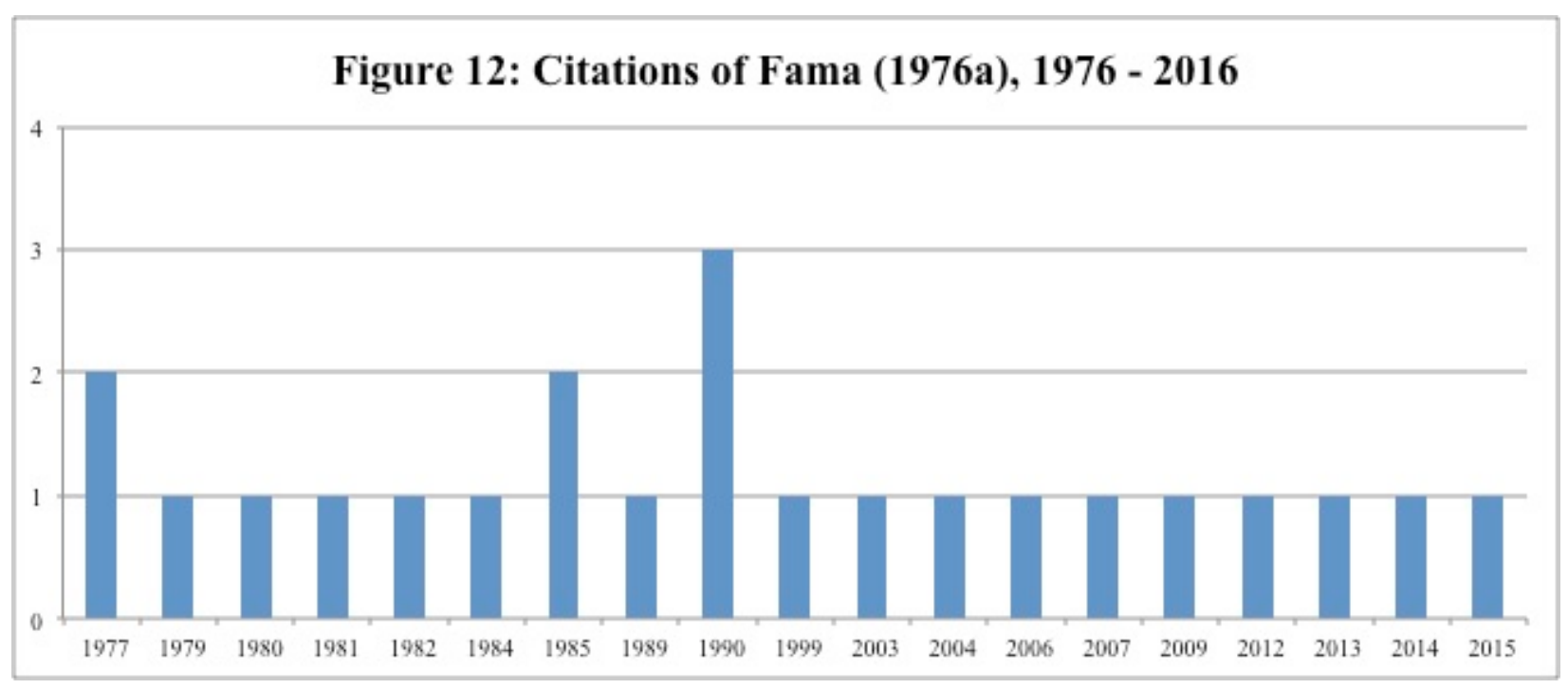

Moreover, 55\% of the articles that cited Fama (1976a) are the same that cited LeRoy (1976), and Fama (1976a) was never cited by authors from the University of Chicago and the University of Rochester, its satellite, excepted one author!

\footnotetext{
${ }^{14}$ However, as remind, that Fama (1976a) explanation was reproduced in Fama largely diffused book, Foundations of finance (1976b).Therefore, it is extremely difficult to measure the impact of Fama (1976a) because Foundations of finance was a textbook largely diffused and the definition of the EMH was one topic among numerous ones.
} 


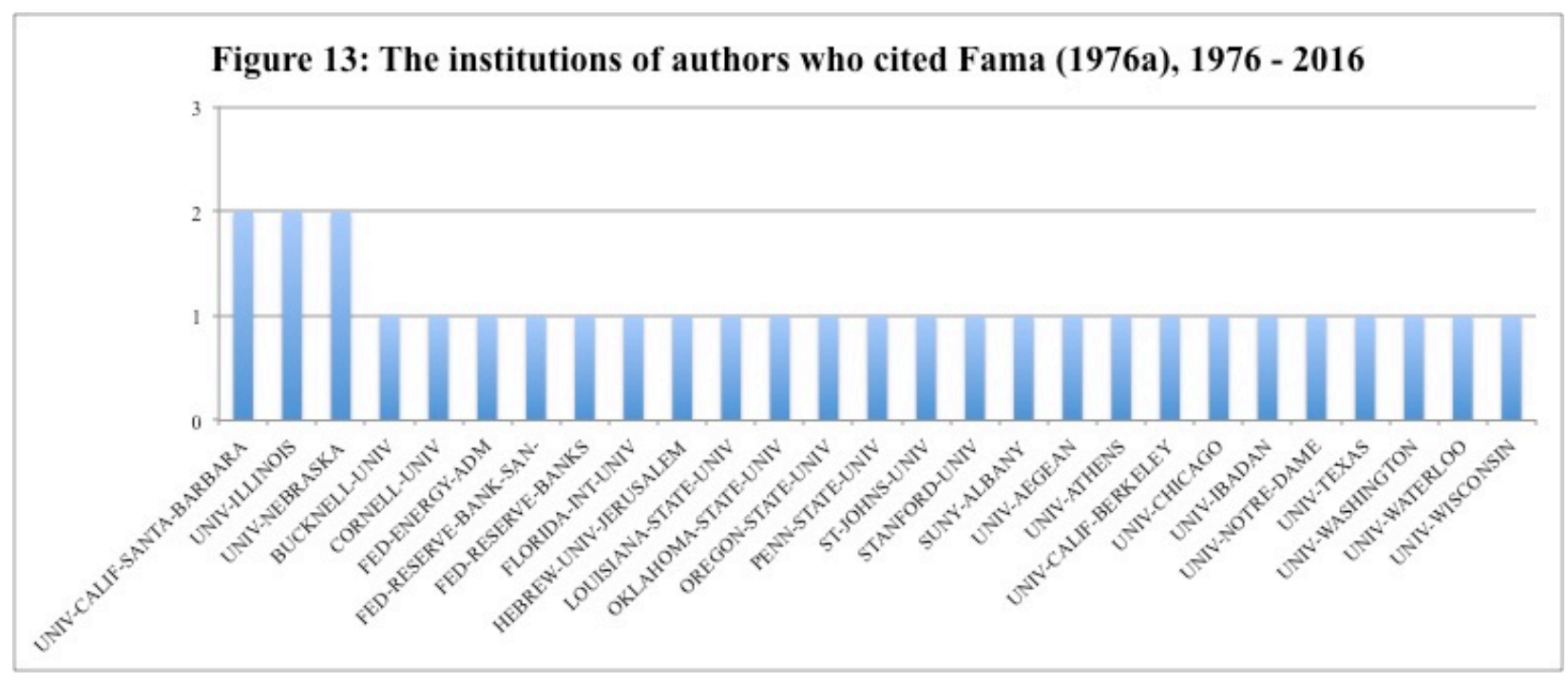

To conclude this third and last example, citation analysis provides a perspective that totally differs from qualitative history. Indeed, the debate between Fama and LeRoy doesn't have a significant influence according to citation analysis. However, considering the qualitative history, the lack of citation does not imply a lack of influence, because Fama changed many times his definition of the EMH, as we can observe with Fama $(1991,1998)$. Therefore, this debate has a significant influence in this kind of story.

\section{Some reflexions from a comparison between qualitative and quantitative history}

From the three moments studied, this last section discusses some relations between quantitative and qualitative histories considering the citation analysis previously used. First of all, it is worth reminding that the citation analysis is only one among many other possibilities for writing a quantitative history (Cherrier 2017, Claveau and Gingras 2016, Claveau and Herfeld 2018, Edwards 2017, Gingras and Schinckus 2012, Polillo 2015, Svorenčík 2018, Weintraub and Düppe 2018). Citation analysis can be considered as the most frequent and easiest quantitative approach that can be used in the history of economics. This method can be completed with other quantitative analyses, like social network analysis, conceptual ontologies, document co-citation analysis ${ }^{15}$, prosopography, etc.

For instance, Polillo (2015) used a social network analysis for studying why the EMH acquired core theoretical status in financial economics whereas the Capital Asset Pricing Model, another central element in this discipline, didn't. This author showed the crucial role of the coherence and the cohesion of the network structure in the succeed of the EMH, and particularly in the succeed of Fama's ideas. For doing this, Polillo (2015) used "all articles published in the four top journals in financial economics [...] from 1981 to 2004". It is difficult to imagine doing similar analysis with qualitative methods for discovering this kind of relations. More precisely, in their very intelligent and intelligible article, Claveau and Herfeld (2018) pointed out how social network analysis, like other quantitative method, "serves foremost as a method of discovery and

\footnotetext{
${ }^{15}$ It can be noticed that I did a "basic" co-citation analysis about Fama (1976a) and LeRoy (1976) manually (i.e. the fact that $55 \%$ of the articles which cite these two articles are the same), because the number of citations is very low. However, for publications largely cited I would have used a deeper document co-citation analysis (Leydesdorff 1998).
} 
confirmation, and not primarily as a method of representation" of relations established from qualitative analysis for instance. According to me, this distinctive feature is important: citation analysis, like other quantitative analysis, allows the discovery of new elements or relations that cannot be established with qualitative methods. This section will clarify this point. Among quantitative methods applied to financial economics that are not used here, we can also mention Pardo-Guerra (2016) article that used conceptual ontologies (i.e. "a representation of discourse within a particular domain that views meaning as formed by how concepts are classified into larger collections and interrelated") for studying the 3068 public speeches of the Securities and Exchange Commission (i.e. roughly 34,000 pages of plain text). With this method, this author can trace, among other things, the influences of the EMH in the American financial markets regulation during seven decades. Here again the statistical evolution about the use of the EMH ideas provides new results about the history of this hypothesis that cannot be obtained from qualitative methods.

The three moments previously studied showed that a combination between quantitative and qualitative analysis can significantly improve the history of economics. In these moments, the citation analyses don't make sense by itself; they need to be complemented with elements from qualitative history in order to capture some historical evolutions. Bachelier's case is a telling example on the way in which quantitative analysis can improve the qualitative analysis in order to develop a more complete history of specific authors or events. In this example, citation analysis appears as a useful method of discovery. In the same vein, Gingras (2008) used a combination of qualitative and quantitative analysis to clarify the contributions of Lorentz, Einstein and Poincaré about relativity theory and to solve the "mystery of the Einstein-Poincaré connection". A quantitative analysis can clearly contribute to improve qualitative interpretations in order to provide better historiographies of economics.

In the same time, in our examples, we saw some divergences between quantitative history and qualitative history. Quantitative history (in our case citation analysis) can capture some evolutions that are not (or are less) studied by qualitative history. For instance, the diffusion of Bachelier's publications or the marginal diffusion of the debate between Fama and LeRoy in the literature. The observation of such divergences is in line with the literature. For instance, the evolution of subject matters, or of the relative importance of theoretical and empirical work (Cherrier 2017, Claveau and Gingras 2016, Daemen 2010, Kelly and Bruestle 2011). Claveau and Gingras (2016) used an algorithm in order to detect patterns in the evolution of specialities in economics from the late 1950 s up to today. I am convinced that such patterns could not be detected in a qualitative analysis. According to De Vroey, "the main shortcoming of Claveau and Gringras's configuration (as far at least as macroeconomics is concerned) is that it misses the logic of the development of this field" $(2016,11)$. However, as we saw in the previous section, quantitative and qualitative histories could present very different histories (or different logic of the development of the EMH). By "contrasting one example of SNA [social network analysis] to an example of a historical study that builds a network representation but does not use the tools of SNA", Claveau and Herfeld (2018) pointed out some elements that can explain such plurality. These authors oppose the heterogeneous information "both in source and in format" used in qualitative analysis to the homogeneous information "both in source and in format" used in quantitative history. This homogeneity comes from, amongst other things, the number of references (around 400,000 articles), while this heterogeneity comes from, amongst other things, "a close reading of published material, especially of who cites whom and for what purposes". Therefore, the quantitative analysis can discover a 
certain logic of the development of economics without having to do a close reading of the 400,000 articles.

Although I didn't use the same amount of data, we observed the same kind of difference in the previous citation analysis: the qualitative history of the EMH we know starts from singular authors or events for providing a story ${ }^{16}$, while quantitative history starts from statistic regularities for providing a story. In this perspective, what is true at the micro level could be not true at the macro level and vice versa. For instance, the macro level can identify a regularity in the evolution of economics that does not exist in the works of a particular author. Fama and LeRoy debate is an example. Considering results from the quantitative analysis, the qualitative history could have overestimated the importance of this debate in the history of the EMH. The fact that qualitative history analyses specific events, authors or ideas could let this kind of history to over-estimate the impact of such debates ${ }^{17}$. By opposition, such debates could be under-estimated in quantitative history. For instance, some gatekeepers might limit the traces of this debate in the scientific journals, but it doesn't mean that the debate did not exist or did not have an impact. Indeed, given that actors from the University of Chicago (who strongly supported Fama's work), controlled the majority of the scientific journals and consequently the publications (Findlay and Williams 2001), we can suspect that debate to be under-estimated in the published work ${ }^{18}$. In this specific case, additional qualitative analysis would be needed in order to interpret quantitative results.

We also saw that citation analysis can have an important limit when we want to compare the importance of articles. This is a crucial point for citation analysis and the quantitative history. As explained, financial economics is much more concerned by testing statistical hypotheses rather than explanations, and technical articles are much more frequent than theoretical articles. Moreover, with the rise of computers and databases, the tendency is of a clear rising number of technical articles. From his quantitative analysis, Daemen (2010) provided useful trends about the evolution of financial economics, particularly the evolution between technical articles and theoretical articles. It is the case for the EMH, more and more articles are technical articles (i.e. financial econometrics) with very small links with theoretical frameworks. For instance, while a stochastic process is neither necessary nor sufficient for testing an efficient market, a large majority of financial econometrics articles refer to Fama (1970). As Daemen explained, "a typical empirical paper in modern finance [...] states a hypothesis which is then checked by the data. This approach can lead to an ad-hoc character of the hypotheses. Indeed, Fama (1998) condemns much of the criticism on established finance theory for this reason. It takes a theory to beat a theory, not a loose collection of observations and anomalies" $(2010,17)$. This evolution exists in virtually all subfields of economics (Backhouse and Cherrier 2017, Hamermesh 2013), and De Vroey $(2016,8)$ pointed out this issue because most of the literature identified by Claveau and Gingras (2016) are econometric works. Moreover, as Polillo (2015) explained the statistical approach adopted in seminal articles of the EMH played a crucial role in the succeed of Fama's prestige. Given this trend, how could we compare a theoretical article, like Cootner's (1962) that has very few citations

\footnotetext{
${ }^{16}$ More precisely, the starting point of the qualitative history of the EMH was what the economists knew and that can be called a canonical history (Jovanovic 2008).

${ }^{17}$ It is worth mentioning that citation analysis does not differentiate between references that are in agreement with the source paper and references that criticize the source paper. However, Polillo $(2015,23)$, discussing the history of the EMH, suggested to "shift attention to networks of prestige, as recently suggested by Collins and Guillen (2012) as a part of a larger model of "mutual halos"" in order to reduce the similar bias we have in citation networks.

${ }^{18}$ Similar problems existed for Econophysics, see Jovanovic and Schinckus (2017) or Gingras and Schinckus (2012).
} 
(Figure 3), to a technical article like Fama et al.'s (1969), which has numerous citations (Figure $14)$ ?
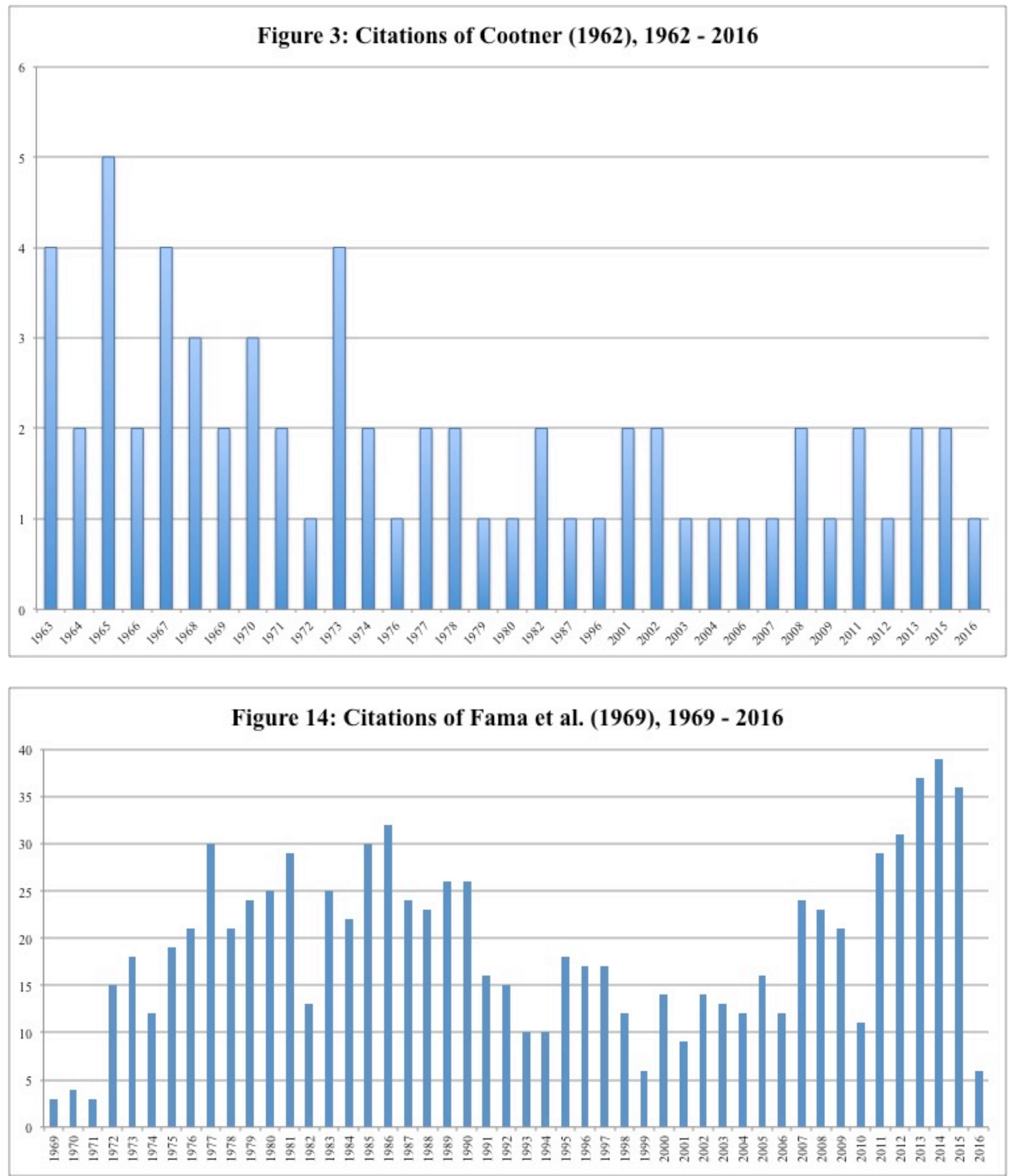

In order to have a perspective on the impact of Cootner (1962), and to compare this article with another one, we should consider the weight of theoretical articles in the total of publications. In 
other terms, we should normalize the data, and therefore choose a benchmark (for instance, the percentage of theoretical articles in the whole publications for instance), in order to compare theoretical articles to technical articles. In the same vein, we should find a way to calibrate the data in order to take into account the control the editorial boards of scientific journals have, as gatekeepers, on the subjects and authors that are published. Indeed, as previously pointed out, gatekeepers can distort the influence of some authors or subjects. One telling example in financial economics is Black and Scholes (1973) article about option pricing, which deeply changed the finance practices and earned Scholes the Sveriges Riksbank Prize in Economic Sciences in Memory of Alfred Nobel (i.e. "Nobel prize") in $1997^{19}$. This famous article was initially rejected by the editorial boards of several scientific journals; it was only when Fama and Miller pressed their contacts at the Journal of Political Economy that the paper was finally published! Creating such benchmarks can be very difficult because it depends on the kind of data we have. In contrast, it is easier for the qualitative analysis to capture this kind of elements (for a singular items).

\section{Conclusion}

Based on an analysis of three moments of the history of the EMH, this article shows how a citation analysis, which is a popular quantitative method, may be used for improving the qualitative history. More precisely, these three moments show that quantitative and qualitative methods applied to the publications of some key articles can provide complementary histories and information. Studying history of Economics by combining bibliometric data and dynamic network analysis, Claveau and Gingras $(2016,585)$ claim that "it is time for historians of economics to use the combined resources of large data, algorithmic methods and computing power". Discussing Claveau and Gingras' article, De Vroey (2016) provides a comparison between "qualitative history" (called "Insideknowledge history" ${ }^{20}$ and a "quantitative history" of macroeconomics. De Vroey $(2016,14)$ points out that the two approaches must be considered as complementary. This conclusion is similar to Claveau and Herfeld (2018) who claim that social network analysis, one of the quantitative methods for studying historical materials, "must be complemented with historical knowledge gained by other means and often by more traditional, mostly qualitative, methods". In this perspective, we may claim that historians of economics should not continue ignoring quantitative analysis.

\section{References}

Bachelier, Louis. 1900. "Théorie de la spéculation reproduced in." Annales de l'Ecole Normale Supérieure, 3ème série 17 (January):21-86. Reprint, 1995, J. Gabay, Paris.

Bachelier, Louis. 1912. Calcul des probabilités. Paris: Gauthier-Villars.

Bachelier, Louis. 1914. Le jeu, la chance et le hasard, Bibliothèque de philosophie scientifique. Paris: E. Flammarion.

Bachelier, Louis. 1921. Notice sur les travaux de M. Louis Bachelier. In La solidarité. Besançon.

Backhouse, Roger, and Béatrice Cherrier. 2017. "Becoming Applied: the Transformation of Economics after 1970." History of Political Economy 49 (forthcoming).

Beaver, Willism H. 1981. "Market efficiency." Accounting Review 6 (2-3):297-330.

\footnotetext{
${ }^{19}$ Black died in 1995 and thus was not eligible for the prize. Scholes shared the prize with Merton.

${ }^{20}$ It is worth mentioning that the "inside-knowledge history" is a very limited vision of qualitative history.
} 
Ben-El-Mechaiekh, Hichem, and Robert W. Dimand. 2018. "Louis Bachelier's 1938 Monograph on the Calculus of Speculation: Mathematical Finance and Randomness of Asset Prices in Bachelier's later work." Revue d'histoire des mathématiques 24 (1):41-106.

Bernstein, Peter L. 1992. Capital ideas : the improbable origins of modern Wall Street. New York and Toronto: Free Press; Maxwell Macmillan Canada; Maxwell Macmillan International.

Black, Fischer, and Myron Scholes. 1973. "The Pricing of Options and Corporate Liabilities." The Journal of Political Economy 81 (3):637-654.

Campbell, John Y., Andrew W. Lo, and Archie Craig MacKinlay. 1997. The econometrics of financial markets. Chichester;Princeton, N.J;: Princeton University Press.

Cherrier, Béatrice. 2017. "Classifying Economics: A History of the JEL Codes." journal of Economic literature 55 (2):545-79.

Claveau, François, and Yves Gingras. 2016. "Macrodynamics of Economics: a bibliometric history." History of Political Economy 48 (4):551-592.

Claveau, François, and Catherine Herfeld. 2018. "Social Network Analysis: A Complementary Method of Discovery for the History of Economics." In A Contemporary Historiography of Economics, edited by E. Roy Weintraub and Till Düppe. Routledge.

Cootner, Paul H. 1962. "Stock prices: Random vs. systematic changes." Industrial Management Review 3 (2): 24.

Cootner, Paul H. 1964. The random character of stock market prices. Cambridge, Mass.: M.I.T. Press.

Courtault, Jean-Michel, Youri Kabanov, Bernard Bru, Pierre Crépel, Isabelle Lebon, and Arnaud Le Marchand. 2002. "Louis Bachelier on the centenary of Théorie de la spéculation." In Louis Bachelier: aux origines de la finance mathématique, edited by Jean-Michel Courtault and Youri Kabanov, 5-86. Besançon: Presses Universitaires Franc-Comtoises.

Cowles, Alfred. 1933. "Can Stock Market Forecasters Forecast?" Econometrica 1 (3):309-324.

Cowles, Alfred. 1944. "Stock Market Forecasting." Econometrica 12 (3/4):206-214.

Cowles, Alfred. 1960. "A Revision of Previous Conclusions Regarding Stock Price Behavior." Econometrica 28 (4):909-915.

Cowles, Alfred, and Herbert E. Jones. 1937. "Some A Posteriori Probabilities in Stock Market Action." Econometrica 5 (3):280-294.

Cuthbertson, Keith. 2004. Quantitative financial economics: stocks, bonds, and foreign exchange. Chichester: John Wiley.

Daemen, Job. 2010. "Ketchup Economics: What is Finance about?" The 14th Annual Conference of the ESHET, Amsterdam, March 2010.

Davis, Mark, and Alison Etheridge. 2006. Louis Bachelier's Theory of speculation. Princeton and Oxford: Princeton university press.

De Vroey, Michel. 2016. "Bibliometric versus Inside-Knowledge History? An Assessment of Claveau and Gingras's "Macrodynamics of Economics: A Bibliometric History"." Université catholique de Louvain, 2016-33, Working paper.

Delcey, Thomas 2017. "Efficient market hypothesis, Eugene Fama and Paul Samuelson: A reevaluation." HES Annual Conference 2017, University of Toronto (Trinity College).

Dimson, Elroy, and Massoud Mussavian. 1999. Foundations of Finance. Aldershot: Dartmouth Publishing Company.

Dimson, Elroy, and Massoud Mussavian. 2000. "Market Efficiency." In The Current State of Business Disciplines, edited by Bhagwan Shri Dahiya, 959-970. Roihtak: Spellbound. 
Dorian, Julien. 2018. "Practices of Using Interviews in History of Contemporary Economics: A Brief Survey." In A Contemporary Historiography of Economics, edited by E. Roy Weintraub and Till Düppe. Routledge.

Ederington, Louis H. 1979. "Aspects of the Production of Significant Financial Research." The Journal of Finance 34 (3):777-786.

Edwards, José. 2017. "Who's who? Bibliometrics and the history of economics." History of Economics Society conference, Trinity College, University of Toronto.

Fama, Eugene F. 1965. "Random Walks in Stock-Market Prices." Financial Analysts Journal 21 (5):55-59.

Fama, Eugene F. 1970. "Efficient Capital Markets: A Review of Theory and Empirical Work." Journal of Finance 25 (2):383-417.

Fama, Eugene F. 1976a. "Efficient Capital Markets: Reply." Journal of Finance 31 (1):143-145.

Fama, Eugene F. 1976b. Foundations of finance: portfolio decisions and securities prices. New York: Basic Books.

Fama, Eugene F. 1991. "Efficient Capital Markets: II." Journal of Finance 46 (5):1575-1617.

Fama, Eugene F. 1998. "Market efficiency, long-term returns, and behavioral finance." Journal of Financial Economics 49 (3):283-306.

Fama, Eugene F., Lawrence Fisher, Michael C. Jensen, and Richard Roll. 1969. "The Adjustment of Stock Prices to New Information." International Economic Review 10 (1):1-21.

Findlay, M. Chapman, and Edward E. Williams. 2001. "A Fresh Look at the Efficient Market Hypothesis: How the Intellectual History of Finance Encouraged a Real "Fraud-on-theMarket"." Journal of Post Keynesian Economics 23 (2):181-199.

Fourcade, Marion, and Rakesh Khurana. 2017. "The Social Trajectory of a Finance Professor and the Common Sense of Capital." History of Political Economy 49 (2):347-384.

Frydman, Roman, and Michael D. Goldberg. 2010. "Efficient market: fictions and reality." Institute for New Economic Thinking, King's College, Cambridge (UK).

Gingras, Yves. 2008. "The Collective Construction of Scientific Memory: The Einstein-Poincaré Connection and its Discontents, 1905-2005." History of Science 46 (1):75-114.

Gingras, Yves, and Christophe Schinckus. 2012. "Institutionalization of Econophysics in the shadow of physics." Journal of the History of Economic Thought 34 (1):109 - 130.

Giraud, Yann. 2018. Textbooks in the history of recent economics: the case of Samuelson's Economics. In A Contemporary Historiography of Economics, edited by E. Roy Weintraub and Till Düppe: Routledge.

Grossman, Sanford J., and Joseph E. Stiglitz. 1980. "The Impossibility of Informationally Efficient Markets." American Economic Review 70 (3):393-407.

Hamermesh, Daniel S. 2013. "Six Decades of Top Economics Publishing: Who and How?" Journal of Economic Literature 51 (1):162-172.

Harrison, J. Michael, and David M. Kreps. 1979. "Martingales and arbitrage in multiperiod securities markets." Journal of Economic Theory 20 (3):381-408.

Harrison, J. Michael, and Stanley R. Pliska. 1981. "Martingales and Stochastic Integrals in the Theory of Continuous Trading." Stochastic Processes and their Applications 11 (3):215260.

Jensen, Michael C. 1978. "Some anomalous evidence regarding market efficiency." Journal of Financial Economics 6 (2-3):95-101.

Jovanovic, Franck. 2000. "L'origine de la théorie financière: une réévaluation de l'apport de Louis Bachelier." Revue d'Economie Politique 110 (3):395-418. 
Jovanovic, Franck. 2008. "The Construction of the Canonical History of Financial economics." History of Political Economy 40 (2):213-242.

Jovanovic, Franck. 2010. "Efficient markets theory." In Encyclopedia of Quantitative Finance, edited by Rama Cont. Chichester (UK): John Wiley \& Sons.

Jovanovic, Franck. 2012. "Bachelier: not the forgotten forerunner he has been depicted as." European Journal for the History of Economic Thought 19 (3):431-451.

Jovanovic, Franck, and Christophe Schinckus. 2017. Econophysics and Financial Economics: An Emerging Dialogue. New York: Oxford University Press.

Kelly, Michael A., and Stephen Bruestle. 2011. "Trend of Subjects Published in Economics Journals 1969-2007." Economic Inquiry 49 (3):658-673.

Kendall, Maurice George. 1953. "The Analysis of Economic Time-Series. Part I: Prices." Journal of the Royal Statistical Society 116:11-25.

LeRoy, Stephen F. 1973. "Risk Aversion and the Martingale Property of Stock Prices." International Economic Review 14 (2):436-446.

LeRoy, Stephen F. 1976. "Efficient Capital Markets: Comment." Journal of Finance 31 (1):139141.

LeRoy, Stephen F. 1989. "Efficient Capital Markets and Martingales." Journal of Economic Literature 27 (4):1583-1621.

Leydesdorff, Loet. 1998. "Theories of citation?" Scientometrics 43:5-25.

Lo, Andrew W. 2000. "Finance: A selective survey." Journal of the American Statistical Association 95 (450):629.

Lucas, Robert E. 1978. "Asset Prices in an Exchange Economy." Econometrica 46 (6):1429-1445.

Malkiel, Burton G. 1992. "Efficient Market Hypothesis." In The New Palgrave Dictionary of Money and Finance, edited by Peter Newman, Murray Milgate and John Eatwell. London: Macmillan.

Mehrling, Perry. 2005. Fischer Black and the Revolutionary Idea of Finance. Hoboken: John Wiley $\&$ Sons.

Merton, Robert C. 1998. "Applications of Option-Pricing Theory: Twenty-Five Years Later." American Economic Review 88 (3):323-349.

Modigliani, Franco, and Merton H. Miller. 1958. "The Cost of Capital, Corporation Finance and the Theory of Investment." The American Economic Review 48 (3):261-297.

Niederhoffer, Victor. 1997. The education of a speculator. New York: John Wiley \& Sons.

Pardo-Guerra, Juan Pablo. 2016. "Where are the market devices? Exploring the links between regulation, markets, and technology at the Securities and Exchange Commission, 19352010." Working paper.

Poitras, Geoffrey, ed. 2006. Pioneers of financial economics: Contributions Prior to Irving Fisher. Vol. 1. Cheltenham, UK ; Northampton, MA: Edward Elgar.

Poitras, Geoffrey. 2009. "From Antwerp to Chicago: The History of Exchange Traded Derivative Security Contracts." Revue d'Histoire des Sciences Humaines 20:11-50.

Poitras, Geoffrey, and Franck Jovanovic, eds. 2007. Pioneers of financial economics: TwentiethCentury Contributions. Vol. 2. Cheltenham, UK ; Northampton, MA: Edward Elgar.

Poitras, Geoffrey, and Franck Jovanovic. 2010. "Pioneers of Financial Economics: Das Adam Smith Irrelevanzproblem?" History of Economics Review 51 (Winter):43-64.

Polillo, Simone. 2015. "Theorizing Efficient Markets: A Sociology of Financial Ideas." European Journal of Sociology 56 (1):11-37.

Regnault, Jules. 1863. Calcul des chances et philosophie de la bourse. Paris: Mallet-Bachelier and Castel. 
Roberts, Harry V. 1959. "Stock-Market "Patterns" and Financial Analysis: Methodological Suggestions." Journal of Finance 14 (1):1-10.

Rubinstein, Mark. 1975. "Securities Market Efficiency in an Arrow-Debreu Economy." American Economic Review 65 (5):812-824.

Samuelson, Paul A. 1973. "Proof that Properly Discounted Present Value of Assets Vibrate Randomly." Bell Journal of Economics 4 (2):369-374.

Scholes, Myron S. 1998. "Derivatives in a Dynamic Environment." American Economic Review 88 (3):350-370.

Sewell, Martin. 2011. "History of the Efficient Market Hypothesis." University College London, $\mathrm{RN} / 11 / 04$, Working paper.

Shafer, Glenn, and Vladimir Vovk. 2005. "The origins and legacy of Kolmogorov's Grundbegriffe". Working paper.

Stone, Lawrence. 1979. "The Revival of Narrative: Reflections on a New Old History " Past \& Present 85 (1):3-24.

Svorenčík, Andrej. 2018. "The Missing Link: Prosopography in the History of Economics." History of Political Economy 50 (3):forthcoming.

Taqqu, Murad S. 2001. "Bachelier and his Times: A Conversation with Bernard Bru." Finance and Stochastics 5 (1):3-32.

Thicke, Michael. 2017. "What is the Efficient Market Hypothesis?" HES Annual Conference 2017, University of Toronto (Trinity College).

Von Plato, Jan. 1994. Creating modern probability: its mathematics, physics, and philosophy in historical perspective, Cambridge studies in probability, induction, and decision theory. Cambridge [England]; New York: Cambridge University Press.

Weintraub, E. Roy, and Till Düppe, eds. 2018. A Contemporary Historiography of Economics: Routledge.

Whelan, S. F., D. C. Bowie, and A. J. Hibbert. 2002. "A Primer in Financial Economics." British Actuarial Journal 8 (1):27-74.

Whitley, Richard Drummond. 1986. "The Rise of Modern Finance Theory: its characteristics as a scientific field and connection to the changing structure of capital markets." In Research in the History of Economic Thought and Methodology, edited by Warren J. Samuels, 147-178. Stanford: JAI Press Inc.

Working, Holbrook. 1934. "A Random-Difference Series for Use in the Analysis of Time Series." Journal of the American Statistical Association 29:11-24.

Working, Holbrook. 1935. "Differential Price Behavior as a Subject for Commodity Price Analysis." Econometrica 3 (4):416-427.

Working, Holbrook. 1956. "New ideas and methods for price research." Journal of Farm Economics 38:1427-1436.

Zuckerman, Ezra W. 2011. "Market Efficiency: A sociological perspective." In Handbook of the sociology of finance, edited by Alex Preda and Karin Knorr-Cetina. Oxford: Oxford University Press. 